\title{
Caracterização operacional de praças de pedágio do estado de São Paulo
}

\author{
Juliana Jerônimo de Araújo1; José Reynaldo Setti²
}

\begin{abstract}
Resumo: O objetivo desta pesquisa foi analisar a operação de praças de arrecadação de pedágio, a fim de fornecer subsídios para o seu projeto e para o estabelecimento de parâmetros e procedimentos para avaliação do nível de serviço. Os dados foram coletados em cinco praças de pedágio do estado de São Paulo. Os aspectos operacionais estudados foram: o processo de chegadas dos veículos às praças; o perfil da velocidade durante a desaceleração dos veículos na entrada da praça; o processo de escolha da cabine pelos motoristas; o processo de atendimento dos veículos nas cabines; o perfil da velocidade durante a aceleração dos veículos na saída da praça; e as velocidades desenvolvidas nas cabines com tecnologia AVI. Através de um modelo de simulação, também se apresenta um método que exemplifica como o nível de serviço das praças poderia ser estimado a partir desses dados.
\end{abstract}

Abstract: The objective of the research presented in this paper was to analyze the operation of toll plazas in order to give subsidies for its project as well as to establish parameters and procedures to evaluate the level of service. The data were collected in five toll plazas in the state of São Paulo. The operational aspects studied were: the vehicle arrival process; the speed profile during deceleration at the toll plaza entrance; the process in which drivers select toll booths; the vehicle processing time at toll booths; the speed profile during acceleration at the toll plaza exit; and the speed at AVI toll booths. Through the use of a simulation model, a method that shows how this data can be used to estimate the level of service of toll plazas is also presented.

\section{INTRODUÇÃO}

No final da década de 1990, a União e alguns estados iniciaram programas de concessão da operação de suas principais rodovias visando a implantação de melhorias e a reversão da progressiva deterioração no sistema rodoviário nacional, causado pela falta de recursos públicos para sua conservação e ampliação. Esses programas de concessões rodoviárias envolvem a instalação de praças de arrecadação de pedágio, uma vez que a remuneração das empresas responsáveis pela operação das rodovias privatizadas é feita através da cobrança de tarifas dos usuários.

Um importante aspecto da concessão de rodovias é o controle da qualidade do serviço prestado aos usuários, que envolve aspectos referentes ao estado do pavimento e da sinalização, aos serviços de assistência ao usuário e à capacidade e nível de serviço dos diversos segmentos. Para o usuário, um dos pontos mais críticos da qualidade do serviço prestado pelas empresas concessionárias é a operação das praças de arrecadação de pedágio. A cobrança de pedágio é um fator que afeta significativamente a percepção do nível de serviço. Demoras excessivas causadas por falhas no projeto, no dimensionamento ou na operação da praça podem influir direta e negativamente na opinião do

\footnotetext{
${ }^{1}$ Juliana Jerônimo de Araújo, Universidade de São Paulo, Escola de Engenharia de São Carlos. São Carlos, SP, Brasil (e-mail: julianajaraujo@gmail.com).

${ }^{2}$ José Reynaldo Setti, Universidade de São Paulo, Escola de Engenharia de São Carlos. São Carlos, SP, Brasil (e-mail: jrasetti@usp.br).
}

Este artigo é parte de TRANSPORTES, volume XIV, número 1, junho de 2006. ISSN: 1415-7713. usuário da rodovia.

\section{OBJETIVO DA PESQUISA}

Uma das razões que inspiraram o desenvolvimento desta pesquisa foi o melhor entendimento dos processos a que são submetidos os veículos ao se aproximarem de uma praça de pedágio. Entende-se que uma caracterização adequada da operação das praças pode fornecer subsídios para o seu projeto e para o estabelecimento de procedimentos e parâmetros para a avaliação do nível de serviço prestado aos usuários. Adicionalmente, buscou-se ainda realizar um estudo de caso para demonstrar como os parâmetros operacionais das praças podem ser usados na avaliação do nível de serviço. Para tanto, fez-se uso de um modelo de simulação.

O estudo procurou caracterizar a operação das praças de pedágio do estado de São Paulo da forma mais realística possível e seus resultados podem contribuir para aumentar a eficiência das praças, ao permitirem a análise de alternativas operacionais e tecnológicas que proporcionem diminuição do tempo de espera nos pedágios e, conseqüentemente, redução do tempo de viagem. Cabe lembrar que esse trabalho complementa o publicado anteriormente por Araújo e Setti (2002).

\section{ETAPAS SEGUIDAS PARA A REALIZAÇÃO DA PESQUISA}

O primeiro passo para o desenvolvimento da pesquisa foi fazer um levantamento do estado da técnica relacionada ao projeto e à operação de praças de pedágio, incluindo inovações tecnológicas e operacionais, medidas de desempenho operacional, técnicas de mode- 
lagem e modelos que representem o seu funcionamento.

A seguir, foram definidos os dados a serem coletados, a avaliação da melhor forma para a coleta desses dados e a escolha de um conjunto de praças de pedágio que representasse as diversas tecnologias e os diversos procedimentos operacionais em uso no estado de São Paulo. Em seguida, foram obtidos os dados necessários para a caracterização do comportamento dos usuários e realizada a análise da operação das praças escolhidas para a coleta de dados.

Por fim, elaborou-se uma proposta de um método para avaliar o nível de serviço de praças de pedágio com base nos dados coletados, nos resultados da análise desses dados e com auxílio de um modelo de simulação.

\section{PESQUISAS DESENVOLVIDAS SOBRE PRAÇAS DE PEDÁGIO}

Diversos modelos analíticos foram desenvolvidos nos últimos anos visando analisar alguns dos parâmetros relativos à operação de praças de pedágio, entre os quais, os elaborados por Zarrillo et al. (1997), Widmer et al. (1999) e Oliveira et al. (2003). O primeiro é um modelo matemático que reflete as condições de tráfego em um praça de pedágio com vários tipos de coleta de tarifa, incluindo a eletrônica. O segundo modelo propõe um algoritmo baseado em modelos estocásticos de filas para a determinação dos turnos de trabalho e do número de cabines em cada turno, de forma a fornecer um nível de serviço predeterminado a um custo operacional mínimo. O modelo elaborado por Oliveira et al. (2003) se propõe a avaliar a influência que o tamanho das filas nas cabines exerce sobre o tempo de atendimento, buscando estimar a interferência das filas no comportamento tanto dos operadores das cabines como dos motoristas.

Outros estudos fizeram uso de Redes Neurais Artificiais, como o desenvolvido por Oliveira e Cybis (2005), em que são apresentados modelos para a previsão de tempos de atendimento em cabines de praças de pedágio com cobrança manual, com a inclusão de diversas variáveis intervenientes nos tempos de atendimentos. Modelagem semelhante foi utilizada por Oliveira et al. (2004) no desenvolvimento de um mecanismo de avaliação do desempenho dos operadores das cabines de pedágio.

Pode-se considerar que para a realização de uma análise global da operação de praças de pedágio, os modelos analíticos ou de Redes Neurais Artificiais não são apropriados, devido à complexidade dos fatores envolvidos. Daí a necessidade de se recorrer à simulação, que permite analisar diversos cenários operacionais, possibilitando assim a comparação de alter- nativas e o efeito que cada uma delas produz sobre o desempenho da praça.

São quatro os principais modelos de simulação de praças de pedágio desenvolvidos nos últimos anos: Lin e Su (1994), Gulewicz e Danko (1995), Burris e Hildebrand (1996) e Al-Deek et al. (2000).

A motivação para a elaboração do modelo desenvolvido por Lin e Su (1994) surgiu do fato de não existir uma metodologia definida para a análise do nível de serviço em praças de pedágio, apesar de a cobrança de pedágio afetar significantemente a fluidez do tráfego. Esse estudo estabeleceu critérios para a análise do nível de serviço baseados no comprimento médio da fila por cabine e no tempo médio no sistema.

O estudo realizado por Gulewicz e Danko (1995) consistiu numa avaliação da quantidade de cabines necessária para manter um nível de serviço aceitável em uma praça de pedágio durante os períodos entre picos de tráfego. Esse estudo fez uma análise para vários níveis de fluxo e composição de tráfego e procurou maximizar a eficiência da operação da praça, considerando o comprimento da fila e a espera média. Nele são apresentados critérios utilizados para a avaliação do nível de serviço baseados no comprimento médio de fila por cabine e no tempo médio de espera.

O modelo de simulação proposto por Burris e Hildebrand (1996) foi usado para analisar o impacto da implantação da coleta eletrônica de pedágio, que faz uso da identificação automática de veículos (AVI), em uma ponte canadense. Para estudar o sistema foi desenvolvido um modelo de simulação que permitia a análise de todos os aspectos do processo de coleta de pedágio, incluindo a desaceleração do veículo, a formação de fila, a lógica da escolha da cabine, o tempo de atendimento e a aceleração do veículo. A modelagem escolhida também permitia a inclusão de diferentes tipos de veículos, formas de pagamento e taxas de ocupação das cabines em função do número de cabines em operação.

Com o intuito de investigar o impacto do uso da tecnologia AVI na operação de praças de pedágio, Al-Deek et al. (2000) desenvolveram um modelo de simulação bastante detalhado. A conclusão obtida foi que os benefícios da AVI dependem da configuração específica da praça. Além disso, um dos mais interessantes resultados desse estudo foi a verificação de que, para todas as configurações de praças simuladas com as cabines manuais operando acima da capacidade, a espera total podia ser reduzida à metade se apenas $10 \%$ dos usuários passassem da cobrança manual para a AVI.

\section{COLETA DE DADOS}

Inicialmente, foram estabelecidos os aspectos a serem 
estudados para a caracterização operacional das praças de pedágio. Dentre eles, foram considerados: o processo de chegada dos veículos às praças, o perfil da velocidade durante a desaceleração dos veículos na entrada da praça, o processo de escolha da cabine pelos motoristas, o processo de atendimento nas cabines, a forma de pagamento da tarifa, o perfil da velocidade durante a aceleração dos veículos na saída da praça e as velocidades desenvolvidas nas cabines AVI.

Para tanto, foi necessário coletar os seguintes dados: headways entre chegadas sucessivas à praça de pedágio, tempo gasto para percorrer a distância entre a entrada da praça de pedágio e as filas nas cabines, comportamento do motorista na escolha da cabine, tempos de atendimento nas cabines (de acordo com a forma de pagamento e o tipo de veículo), tempo gasto para percorrer a distância entre a saída das cabines e a saída da praça de pedágio e distribuição de velocidades nas faixas AVI.

As praças de pedágio escolhidas para servir de base para este trabalho possuíam características de tráfego e operacionais bastante diversificadas e foram selecionadas com o intuito de caracterizar de uma maneira realística tanto o comportamento dos usuários como a forma com que as concessionárias operam as praças.

Três concessionárias de rodovias do estado de São Paulo colaboraram com o desenvolvimento deste estudo, permitindo e auxiliando na coleta de dados em algumas de suas praças. As praças escolhidas foram:

- Araraquara, localizada no km 282 da SP-310 (Rodovia Washington Luiz) e operada pela Triângulo do Sol;

- Campo Limpo, localizada no km 39 da SP-348 (Rodovia dos Bandeirantes) e operada pela AutoBAn;

- Limeira, localizada no km 152 da SP-330 (Rodovia Anhangüera) e operada pela AutoBAn;

- Nova Odessa, localizada no km 118 da SP-330 (Rodovia Anhangüera) e operada pela AutoBAn; e

- Sertãozinho, localizada no km 327 da SP-322 (Rodovia Atílio Balbo) e operada pela Vianorte.

Em cada praça foram realizadas várias coletas de dados, em dias da semana e até em meses diferentes. Dessa forma, foram obtidos dados relativos a diferentes características de tráfego e operacionais, o que contribuiu para a generalização dos dados.

\section{ANÁLISE DOS DADOS COLETADOS}

Durante a realização das coletas de dados, das cinco praças estudadas apenas duas possuíam cobrança bidirecional no período da coleta de dados: Araraquara e Sertãozinho. Para a descrição do sentido de cobrança de pedágio nas praças, designa-se sentido Norte o sen- tido capital-interior e sentido Sul o sentido interiorcapital. As praças de Campo Limpo, Limeira e Nova Odessa cobravam pedágio apenas no sentido Norte.

\subsection{Processo de chegadas}

A aquisição de dados para análise do processo de chegadas dos veículos foi feita a partir da instalação de dois sensores automáticos para coleta de dados nas faixas da entrada da praça de Araraquara, no sentido Sul. A duração total da coleta foi de 6 horas e obtevese uma amostra de 2.154 veículos. A coleta de dados em apenas um sentido da praça deu-se em função da restrição no número de sensores disponíveis.

Durante a análise dos dados, foi verificada uma variação no fluxo médio horário, indicando que o processo de chegadas não poderia ser analisado para o período de seis horas como um todo. Assim sendo, o processo de chegadas foi estudado em termos das distribuições observadas de headways para cada uma das seis horas separadamente. Através do conhecimento do instante de passagem de cada veículo, foi possível obter uma distribuição dos headways para cada hora observada e, a partir dessa distribuição, fazer um estudo para verificar qual distribuição teórica mais se aproximava da observada. Admitiu-se, como hipótese nula, que os headways observados dentro de cada hora analisada obedeciam a uma distribuição exponencial negativa.

Utilizando-se o teste de Kolmogorov-Smirnov, com nível de significância de $5 \%$, verificou-se que não existiam indícios contrários à hipótese de que os headways pudessem ser modelados por uma distribuição exponencial negativa. Deve-se ressaltar que esta conclusão, a priori, aplica-se apenas à praça estudada, já que situações excepcionais em outras praças poderiam prever a existência de um regime poissoniano de chegadas; isto posto, deve-se também ressaltar que é perfeitamente adequado supor que as chegadas à praça sejam poissonianas, a menos que existam evidências de que este regime não seja adequado para representar o processo de chegadas.

\subsection{Perfis da desaceleração e da aceleração}

Ao chegar a uma praça de pedágio, os veículos passam por um ciclo composto por três estágios: desaceleração (para que seja possível efetuar o pagamento da tarifa na cabine), espera pelo atendimento (na fila ou na cabine) e aceleração (até retornar à sua velocidade de cruzeiro).

Os dados sobre o primeiro e o terceiro estágios desse ciclo foram coletados na praça de Araraquara, através de câmeras de vídeo. A duração da coleta foi de 7 horas, no caso da desaceleração, e de 6 horas, no caso da aceleração. A desaceleração foi coletada no sentido Sul e a aceleração, no sentido Norte. Nessa praça, devido ao baixo fluxo de tráfego, as filas eram pratica- 
mente inexistentes. Foram consideradas três classes veiculares: automóveis, caminhões e ônibus.

A amostra da desaceleração era composta por 1.731 veículos, sendo 1.282 automóveis (74,06\%), 412 caminhões $(23,80 \%)$ e 37 ônibus $(2,14 \%)$. Na aceleração, foram observados 2.266 veículos: 1.606 automóveis $(70,87 \%), 633$ caminhões $(27,93 \%)$ e 27 ônibus $(1,20 \%)$.

Bennett e Dunn (1995) dividem as pesquisas que têm sido feitas sobre a modelagem do comportamento da desaceleração e da aceleração dos motoristas em rodovias essencialmente em quatro áreas distintas, em função do modelo adotado: modelos constantes, modelos linearmente decrescentes, modelos polinomiais e modelos baseados na potência dos veículos.

Devido à complexidade dos modelos linearmente decrescentes e à falta dos dados necessários para a construção de um modelo polinomial ou de um modelo baseado na potência dos veículos, admitiu-se neste estudo a hipótese de que os veículos desaceleram e aceleram a uma taxa constante. Para validação de tal hipótese, foi feita uma comparação entre as velocidades calculadas através dessa hipótese com velocidades medidas através de sensores instalados na entrada e na saída da praça.

As velocidades de cruzeiro na chegada e na saída da praça foram obtidas cronometrando-se o tempo que os veículos gastam para percorrer a praça. Conhecendose a distância percorrida e supondo que a velocidade inicial (no caso da aceleração) ou que a velocidade final (no caso da desaceleração) era igual a zero, foi possível calcular a velocidade na entrada e na saída da praça.

As velocidades assim calculadas foram comparadas com as velocidades medidas pelos sensores instalados na entrada e na saída da praça. Observou-se que as velocidades calculadas estavam ligeiramente superestimadas, apresentando uma diferença média de 4,33\%, que em parte pode ser atribuída ao erro provocado pela paralaxe ao se obter os tempos de percurso na praça.

Entretanto, considerou-se que a suposição feita (acelerações constantes) poderia ser aceita, visto que as formas alternativas de coleta de dados de velocidade seriam inviáveis face aos recursos disponíveis. A utilização de sensores automáticos para a determinação dos perfis de velocidade implicaria no uso de um grande número desses sensores devido à enorme variação nas trajetórias de veículos ao longo da praça, causada pelo grande número de faixas e pela programação da operação da praça, que varia as cabines em funcionamento ao longo do dia.

\subsection{Escolha da cabine}

A aquisição de dados sobre o processo de escolha da cabine pelos motoristas foi feita a partir de filmagens feitas na entrada das praças de Araraquara e Limeira. A duração total das coletas foi de 7 horas na praça de Araraquara e de 3 horas na praça de Limeira.

O procedimento adotado para a análise foi a observação isolada de cada veículo e a verificação do lado de chegada à praça (direito ou esquerdo) e da cabine de destino. A amostra total das duas praças era composta por 4.003 veículos, sendo 2.706 automóveis $(67,60 \%), 1.180$ caminhões $(29,48 \%)$ e 117 ônibus $(2,92 \%)$.

A partir da observação das fitas, foram observados cinco hábitos globais relativos ao comportamento dos motoristas:

- a grande maioria dos motoristas (72,78\%) escolhia a cabine no mesmo lado em que chegava à praça de pedágio;

- uma vez selecionado o lado da praça, $88,70 \%$ dos motoristas se dirigiam à cabine com a menor fila naquele lado;

- caminhões e ônibus tendiam a usar as cabines do lado direito da praça. Provavelmente isso tenha ocorrido devido à sinalização nas praças, que induz esse comportamento. Constatou-se que era rara a existência de veículos pesados no lado esquerdo das praças;

- motoristas de automóveis preferiam enfrentar filas de automóveis a enfrentar filas de caminhões, mesmo quando a quantidade de caminhões em fila era muito menor que a de automóveis; e

- alguns motoristas se dirigiam a uma cabine com fila mesmo quando havia cabines disponíveis para o atendimento naquele lado da praça. $\mathrm{Na}$ maioria das vezes, isso ocorre devido a não observação dos sinais luminosos sobre as cabines. Esses sinais indicam se a cabine está em operação ou não.

Outro comportamento observado, porém bastante raro, foi a realização de manobras arriscadas, com várias mudanças de faixas até a chegada à cabine. Esse comportamento foi observado inclusive em motoristas de veículos pesados e, segundo informações obtidas nas concessionárias, é considerado a maior causa de acidentes nas praças.

\subsection{Tempos de atendimento}

Os dados sobre os tempos de atendimento nas cabines que operam através dos métodos tradicionais de cobrança de pedágio foram obtidos nas cinco praças. A duração da coleta foi de 9 horas na praça de Araraquara, 4 horas na praça de Campo Limpo, 5 horas na praça de Limeira, 4 horas na praça de Nova Odessa e 8 horas na praça de Sertãozinho. Esses dados foram obtidos através de filmagens nas praças, com exceção da 
praça de Sertãozinho (onde os dados foram coletados através de um pesquisador dentro da cabine). Durante a análise foram consideradas três classes veiculares: automóveis, caminhões e ônibus.

O tempo de atendimento foi considerado como sendo o tempo compreendido entre duas descidas sucessivas da cancela que libera os veículos nas cabines, quando havia fila. Quando não existia fila, o tempo de atendimento foi considerado como o tempo compreendido entre o momento em que o veículo parava na cabine para ser atendido e o momento em que a cancela descia após a sua passagem, liberando a cabine para outro veículo.

Durante a análise dos dados, verificou-se que a probabilidade de ocorrência de tempos superiores a 60 segundos era muito baixa, em torno de $1 \%$, e correspondia a situações excepcionais (por exemplo, problemas mecânicos impedindo a partida do veículo após o pagamento da tarifa). Assim sendo, tempos de atendimento superiores a 60 segundos foram desprezados. Foi considerado na análise um total de 10.257 veículos, sendo 7.911 automóveis $(77,13 \%), 2.148$ caminhões $(20,94 \%)$ e 198 ônibus $(1,93 \%)$.

O procedimento seguido para a coleta de dados dos tempos de atendimento nas cabines AVI foi diferente do seguido para as formas de cobrança tradicionais. Levando-se em conta que ainda existia um baixo percentual de uso dessa tecnologia, seria inviável coletar dados através de câmeras devido ao tempo que seria gasto para a obtenção de uma amostra de tamanho adequado. Optou-se, então, por usar sensores automáticos para a coleta de dados de velocidade e tipo de veículo nas cabines AVI.

Uma coleta preliminar de 5 horas em duas cabines da praça de Araraquara foi realizada com o objetivo de verificar se existia variação na velocidade desenvolvida pelos veículos dentro das cabines AVI. Constatou-se que os veículos mantinham uma velocidade praticamente constante na entrada e na saída da faixa: a variação média foi de $2,08 \%$.

Desse modo, foram instalados dois sensores nas duas cabines AVI da praça de Araraquara, uma no sentido Sul e outra no sentido Norte. Esses sensores permaneceram instalados por uma semana. Ao contrário dos métodos convencionais de cobrança de pedágio, verificou-se que nas cabines dotadas com AVI não existiam diferenças significativas com relação ao atendimento das classes veiculares, tornando desnecessária a estratificação desses dados.

A amostra era composta por 3.945 veículos que desenvolveram velocidades variando entre 20 e $90 \mathrm{~km} / \mathrm{h}$. Por questões de segurança, a velocidade regulamentada para essas cabines é de $40 \mathrm{~km} / \mathrm{h}$. Com os dados de velocidades e sabendo que existe uma distância de segurança de $30 \mathrm{~m}$ que deve ser mantida entre dois veí- culos sucessivos nas faixas AVI, foi possível calcular os tempos de atendimento.

\subsubsection{Efeito das classes veiculares sobre o tempo de atendimento}

A hipótese de que classes veiculares diferentes têm tempos de processamento diferentes foi criada a partir da observação empírica do atendimento de veículos e da revisão bibliográfica (Lin e Su, 1994; Gulewicz e Danko, 1995; Burris e Hildebrand, 1996; Al-Deek et al., 2000). A opção por dividir os veículos em três classes surgiu a partir da revisão bibliográfica realizada (Lin e Su, 1994; Gulewicz e Danko, 1995; Burris e Hildebrand, 1996), que sugeria diferenças relevantes no atendimento de alguns tipos de veículos através dos métodos tradicionais de cobrança de pedágio.

Como esperado, a média dos tempos de atendimento dos automóveis $(18,92 \mathrm{~s})$ ficou abaixo das médias dos tempos dos caminhões (30,79 s) e ônibus $(23,96$ s). Esse fato é ocasionado por vários fatores, entre eles: o baixo poder de aceleração dos veículos pesados, a dificuldade na transação gerada pela altura dos caminhões e ônibus em relação às cabines e a largura das faixas laterais às cabines, que quando são muito estreitas fazem com que os veículos pesados se movimentem de forma mais lenta que o normal, a fim de evitar acidentes.

Alguns parâmetros estatísticos dos tempos de atendimento para as três classes veiculares estão mostrados na Tabela 1. Para verificar se a diferença encontrada entre os tempos de atendimento dos caminhões e ônibus era significativa, fez-se uso de análise de variância (ANOVA). O resultado indicou que, para um nível de significância de 5\%, existia uma diferença significativa entre os tempos de atendimento dos ônibus e dos caminhões. Esse resultado já era esperado, visto que o tempo médio de atendimento dos ônibus é cerca de $22 \%$ menor que o dos caminhões.

Tabela 1: Parâmetros relativos aos tempos de atendimento (em segundos), em função da classe veicular

\begin{tabular}{lccc}
\hline \multirow{2}{*}{ Parâmetros } & \multicolumn{3}{c}{ Classe Veicular } \\
\cline { 2 - 4 } & Automóveis & Caminhões & Onnibus \\
\hline Média & 18,92 & 30,79 & 23,96 \\
Desvio-Padrão & 10,18 & 14,13 & 9,70 \\
Mediana & 16,00 & 28,00 & 22,00 \\
Moda & 13,00 & 20,00 & 16,00 \\
Tamanho da & 7.911 & 2.148 & 198 \\
amostra & & & \\
\hline
\end{tabular}

\subsubsection{Efeito da praça sobre o tempo de atendimento}

Outro aspecto verificado durante a análise dos dados visava determinar se existiam diferenças nos tempos de atendimento de praça para praça.

Os tempos de atendimento observados para as cinco 
praças seguem as distribuições mostradas na Figura 1, para todos os tipos de veículos. Através dela, pode-se observar que as três praças operadas pela mesma concessionária (Campo Limpo, Nova Odessa e Limeira) possuem distribuições semelhantes. Isso sugere que as características físicas e operacionais das praças, que obedecem a padrões estabelecidos pela concessionária, podem influir diretamente no tempo gasto para os veículos serem processados.

As médias dos tempos de atendimento para as três classes veiculares nas cinco praças de pedágio são apresentadas na Tabela 2. A análise de variância (ANOVA) foi usada para verificar se as diferenças encontradas entre os tempos de atendimento das praças operadas pela mesma concessionária e entre os tempos de atendimento para as três classes veiculares nessas mesmas praças eram significativas. Concluiuse que, para $\alpha=5 \%$, não existe um efeito significativo da praça sobre o tempo de atendimento, reforçando o resultado da análise anterior. Entretanto, verificou-se um efeito significativo do tipo de veículo sobre o tempo de atendimento nas praças da mesma concessionária.

\subsubsection{Efeito do valor da tarifa sobre o tempo de atendimento}

Os dados coletados sugerem que o valor da tarifa pode ter influência direta na distribuição dos tempos de atendimento da praça. A partir dos dados apresentados, pode-se verificar que na praça de Sertãozinho os tempos de atendimento são consideravelmente inferiores aos tempos das demais praças, em todas as classes.

Ao contrário das outras quatro praças, a tarifa em
Sertãozinho durante a coleta de dados era inteira, ou seja, não existiam centavos. Desse modo, facilitava-se a transação não só por parte do operador da cabine, que agilizava o atendimento, como também por parte do usuário, que diminuía o tempo gasto na verificação do troco.

A cobrança de tarifa inteira leva a reduções substanciais no tempo de processamento: contrastando o valor da média dos tempos de atendimento dessa praça com a média global, verifica-se uma redução de aproximadamente $30 \%$ nos tempos dos automóveis, $26 \%$ nos tempos dos caminhões e $34 \%$ nos tempos dos ônibus.

Através de uma análise de variância (ANOVA), verificou-se se existia um efeito do valor da tarifa e do tipo de veículo sobre o tempo de atendimento. Ao nível de significância de $5 \%$, constatou-se a existência de um efeito significativo para as duas variáveis analisadas e de um efeito significativo de segunda ordem da combinação dessas duas variáveis sobre o tempo de atendimento.

\subsubsection{Efeito do fluxo de tráfego da praça sobre o tempo de atendimento}

A revisão bibliográfica realizada (Lin e $\mathrm{Su}, 1994$; $\mathrm{Gu}-$ lewicz e Danko, 1995; Burris e Hildebrand, 1996) sugeria que o fluxo de tráfego das praças de pedágio podia influenciar no tempo de atendimento. Isso pode ser explicado através de dois fatores:

- o comportamento dos operadores das cabines, que se sentem pressionados por uma fila crescente e tendem a executar a transação com maior rapidez; e

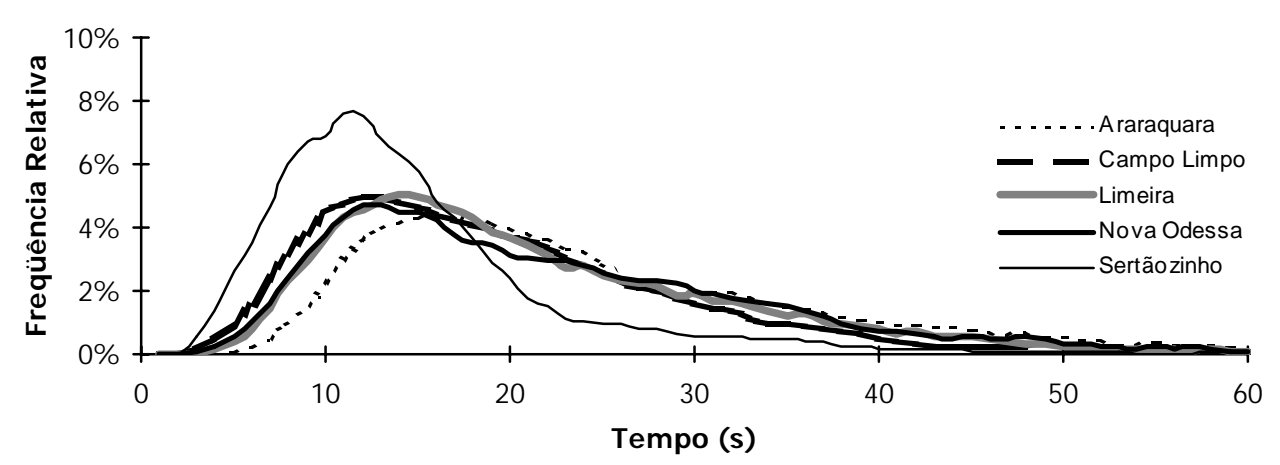

Figura 1: Distribuição dos tempos de atendimento dos veículos nas praças, sem estratificação por tipo de veículo

Tabela 2: Médias dos tempos de atendimento (em segundos), em função da praça de pedágio

\begin{tabular}{cccc}
\hline \multirow{2}{*}{ Praça } & \multicolumn{3}{c}{ Classe Veicular } \\
\cline { 2 - 4 } & Automóveis & Caminhões & Onibus \\
\hline Araraquara & 22,28 & 34,66 & 25,74 \\
Campo Limpo & 18,81 & 25,82 & 25,65 \\
Limeira & 18,61 & 31,41 & 26,14 \\
Nova Odessa & 18,61 & 32,14 & 24,76 \\
Sertãozinho & 13,29 & 22,64 & 15,69 \\
\hline
\end{tabular}


- o comportamento dos usuários, que, uma vez na fila, dispõem de tempo para providenciar uma quantia que minimize o seu tempo de atendimento.

Para verificar a influência do fluxo de tráfego sobre o tempo de atendimento, fez-se uso da análise de variância. O fluxo foi classificado em três níveis (alto, médio e baixo), atribuídos em função do tráfego médio diário de cada praça. A Tabela 3 apresenta a classificação das praças em função do fluxo de tráfego.

Tabela 3: Classificação das praças em função do fluxo de tráfego

\begin{tabular}{ccc}
\hline Praça & $\begin{array}{c}\text { Fluxo de Tráfego } \\
\text { Médio Diário (veíc) }\end{array}$ & Classificação \\
\hline Araraquara & $11.690^{*}$ & baixo \\
Campo Limpo & 50.302 & alto \\
Limeira & 20.974 & médio \\
Nova Odessa & 31.975 & alto \\
Sertãozinho & $14.324^{*}$ & baixo \\
\hline * tráfego médio diário dos dois sentidos da praça &
\end{tabular}

O resultado indicou que, ao nível de significância de $5 \%$ :

- existe um efeito significativo do fluxo de tráfego sobre o tempo de atendimento, considerando todas as praças e tipos de veículos;

- existe um efeito significativo do tipo de veículo sobre o tempo de atendimento; e

- existe um efeito significativo da interação fluxo de tráfego e tipo de veículo sobre o tempo de atendimento.

Outra análise de variância foi realizada para verificar o efeito dessa mesma variável (fluxo de tráfego) sobre os tempos de atendimento das praças operadas pela mesma concessionária. Para $\alpha=5 \%$, o resultado indicou que tanto o fluxo de tráfego quanto o tipo de veículo exercem um efeito significativo sobre os tempos de atendimento observados nas três praças operadas pela mesma concessionária (Limeira, Nova Odessa e Campo Limpo).

\subsubsection{Efeito do sentido de fluxo sobre o tempo de atendimento}

Durante o processo de coleta de dados, duas das cinco praças de pedágio estudadas possuíam cobrança bidirecional: Araraquara e Sertãozinho. Como os dados obtidos na praça de Sertãozinho não foram coletados de forma que os dois sentidos de cobrança tivessem amostra de mesma magnitude, foram utilizados apenas os dados obtidos na praça de Araraquara para avaliar se existia alguma relação entre os tempos de atendimento e o sentido de cobrança, em função do tipo de veículo.

Ao nível de significância de 5\%, constatou-se que não existe efeito significativo do sentido de cobrança sobre o tempo de atendimento e nem efeito significa- tivo de segunda ordem da combinação do sentido de cobrança e do tipo de veículo.

\subsubsection{Efeito do tipo de usuário sobre o tempo de atendimento}

O tipo de usuário de uma praça de pedágio pode ter influência no tempo de atendimento nas cabines. Usuários que passam pela praça com muita freqüência, chamados de commuters, geralmente se comportam de forma diferente daqueles que a utilizam esporadicamente.

Os commuters, pessoas que viajam diariamente para se deslocar de sua residência até o local de trabalho, procuram reduzir ao máximo o seu tempo de viagem, levando à adoção de medidas que visem diminuir o tempo gasto para o pagamento da tarifa do pedágio.

Para verificar o efeito do tipo de usuário no tempo de atendimento nas cabines, fez-se uso de análise de variância. Para isso, as praças foram classificadas de acordo com seu tipo de usuário predominante, apresentado na Tabela 4. O resultado da ANOVA indicou que, para $\alpha=5 \%$, existe um efeito significativo do tipo de usuário sobre o tempo de atendimento.

Tabela 4: Classificação das praças em função do tipo de usuário

\begin{tabular}{lc}
\hline \multicolumn{1}{c}{ Praça } & Tipo de Usuário \\
\hline Araraquara & non-commuter \\
Campo Limpo & commuter \\
Limeira & non-commuter \\
Nova Odessa & misto \\
Sertãozinho & commuter \\
\hline
\end{tabular}

\subsubsection{Efeito da forma de pagamento sobre o tempo de atendimento}

Apenas duas praças de pedágio foram utilizadas para coletar dados sobre a forma de pagamento da tarifa pelos usuários. Na praça de Araraquara, durante a fase de coleta de dados, os usuários podiam fazer o pagamento com dinheiro, cartão de crédito e cupom. $\mathrm{Na}$ praça de Sertãozinho, eles podiam utilizar dinheiro, cupom e um cartão desenvolvido pela concessionária, que usa um sistema touchless, ou seja, que não requer contato físico para a sua leitura.

Outra forma de pagamento aceita por todas as concessionárias do estado de São Paulo é o cheque, porém, como o procedimento para atender esses usuários é diferente dos demais (eles são liberados nas cabines e devem parar nas laterais da praça para fazer o preenchimento do valor), esses dados ficaram fora da coleta.

Analisando-se os dados coletados, verificou-se que um baixo percentual de usuários recorria ao pagamento através de cupom (uma média de 2,39\% nas duas praças). Desse percentual, $72 \%$ eram motoristas de caminhões. Além disso, essa forma de pagamento ten- 
dia a não existir num futuro muito próximo, visto que os órgãos responsáveis pelos cupons já haviam interrompido sua comercialização. Por todos esses fatores, desconsiderou-se essa forma de pagamento na análise.

Dos veículos observados na praça de Araraquara, 91,24\% utilizaram dinheiro para o pagamento da tarifa. Na praça de Sertãozinho, esse percentual era de $85,99 \%$. O cartão de crédito foi usado por $4,20 \%$ dos usuários em Araraquara e o cartão inteligente, por 12,94\% dos usuários em Sertãozinho.

A Tabela 5 apresenta as médias observadas dos tempos de atendimento de acordo com a forma de pagamento. Através dela percebe-se que para o pagamento em dinheiro, a média do tempo de atendimento em Sertãozinho foi consideravelmente menor que em Araraquara. A principal justificativa para tal deve-se ao fato de que o valor da tarifa em Sertãozinho era inteiro, ou seja, sem centavos. Além disso, pode-se observar que a adoção de uma tecnologia como a do cartão inteligente pode gerar grandes benefícios para a operação de uma praça de pedágio.

Tabela 5: Médias dos tempos de atendimento (em segundos), em função da praça de pedágio

\begin{tabular}{cccc}
\hline \multirow{2}{*}{ Praça } & \multicolumn{3}{c}{ Forma de Pagamento } \\
\cline { 2 - 4 } & Dinheiro & $\begin{array}{c}\text { Cartão de } \\
\text { Crédito }\end{array}$ & $\begin{array}{c}\text { Cartão } \\
\text { Inteligente }\end{array}$ \\
\hline Araraquara & 24,28 & 24,17 & - \\
Sertãozinho & 15,17 & - & 9,88 \\
\hline
\end{tabular}

\subsection{Coleta eletrônica de pedágio}

Os dados coletados nas cabines que operam com a tecnologia AVI indicam que aproximadamente 58\% dos veículos desenvolvem a velocidade regulamentada de $40 \mathrm{~km} / \mathrm{h}$ (tempo de atendimento igual a $3 \mathrm{~s}$ ), 17\% desenvolvem velocidades superiores e $25 \%$, inferiores. Os veículos que passam pelo sistema em velocidade superior ao limite estabelecido fazem-no porque têm conhecimento da capacidade de leitura de informações da tecnologia AVI. Alguns adquirem esse conhecimento através da própria experiência de passagem pelo sistema.

Como as cabines do sistema AVI implantado pelas concessionárias paulistas são padronizadas, pode-se considerar que o comportamento dos usuários nas cabines AVI dessa praça reflete o comportamento dos usuários em todo o estado de São Paulo.

\subsubsection{Efeito da coleta eletrônica de pedágio sobre o tempo de atendimento}

A coleta eletrônica de pedágio reduz drasticamente o tempo de atendimento dos veículos em uma praça. Isto pode ser observado através da comparação feita entre os tempos de atendimento das quatro formas de pagamento apresentadas anteriormente e o tempo gasto nas cabines AVI. A Tabela 6 apresenta alguns parâmetros estatísticos dos tempos de atendimento para as cinco formas de pagamento.

Visando avaliar se as diferenças encontradas entre os tempos de atendimento das cinco formas de pagamento eram estatisticamente significativas, utilizou-se a análise de variância considerando-se apenas automóveis na análise, já que a porcentagem de caminhões que usam cartão de crédito é muito pequena e não se conseguiu observar nenhum ônibus usando essa forma de pagamento. A partir dos resultados da ANOVA, concluiu-se que, ao nível de significância de 5\%, existe um efeito do tipo de pagamento sobre o tempo de atendimento.

O Teste de Scheffé, considerado mais apropriado para comparações que não sejam pareadas, também foi utilizado para verificar se existiam diferenças significativas entre os tempos de atendimento das formas de pagamento. Os resultados indicaram que as diferenças entre as médias dos tempos de atendimento para cada forma de pagamento são estatisticamente significativas ao nível de confiança $\alpha=10 \%$, a menos do pagamento em dinheiro e pagamento com cartão de crédito, cujos tempos médios de atendimento não são estatisticamente diferentes.

O tempo de atendimento dos veículos é considerado muito importante na análise da operação de praças de pedágio porque ele está diretamente relacionado à capacidade delas. Além disso, a determinação do nível de serviço tem sido baseada no tempo médio gasto no sistema e no comprimento médio da fila, ambos derivados do tempo gasto no atendimento.

\section{MODELO DE SIMULAÇÃO PROPOSTO}

A criação de um modelo de simulação visava ilustrar como os dados coletados para a caracterização da operação das praças poderiam ser utilizados na avaliação

Tabela 6: Parâmetros relativos aos tempos de atendimento (em segundos), em função da forma de pagamento

\begin{tabular}{lccccc}
\hline \multirow{2}{*}{ Parâmetros } & \multicolumn{5}{c}{ Forma de Pagamento } \\
\cline { 2 - 6 } & Dinheiro & Dinheiro sem Troco & Cartão de Crédito & Cartão Inteligente & AVI \\
\hline Média & 24,28 & 15,17 & 24,17 & 9,88 & 3,19 \\
Desvio-Padrão & 11,38 & 7,75 & 10,79 & 4,94 & 0,87 \\
Mediana & 21,00 & 13,00 & 20,00 & 8,00 & 3,00 \\
Moda & 13,00 & 10,00 & 16,00 & 7,00 & 3,00 \\
Tamanho da Amostra & 521 & 804 & 24 & 121 & 3.945 \\
\hline
\end{tabular}


do seu nível de serviço. Em vista disso, o modelo desenvolvido é bastante simplificado.

$O$ simulador usado nesta pesquisa foi $o$ INTEGRATION, cuja descrição detalhada pode ser facilmente encontrada na literatura (Van Aerde, 2000). A praça de pedágio simulada é fictícia e possui cinco cabines em operação, sendo uma delas uma cabine AVI. Na simulação, foram consideradas três classes veiculares: automóveis, caminhões e veículos portadores de AVI. Com base nos resultados das análises realizadas, a diferença entre automóveis e caminhões refere-se ao seu tempo de processamento na cabine de pedágio. Os ônibus foram deixados de lado por representarem uma fração muito pequena do tráfego observado. Os veículos portadores de tags AVI são considerados uma única classe, já que os tempos de processamento observados independem da classe veicular.

$\mathrm{Na}$ rede modelada, cada veículo percorre uma distância de $1.700 \mathrm{~m}$, sendo $600 \mathrm{~m}$ dentro da praça de pedágio. Essa diferença deve-se ao fato da rede abranger não só a praça de pedágio, mas também uma parte da rodovia antes e depois da praça. A construção da rede foi baseada em um projeto de uma praça de pedágio cedido pela Triângulo do Sol, uma das concessionária de rodovias do estado de São Paulo.

$\mathrm{Na}$ estruturação da simulação, os dados coletados foram usados dentro do possível, uma vez que o INTEGRATION, sendo um modelo "genérico" de simulação de tráfego, tem limitações que restringem o seu refinamento. $\mathrm{O}$ regime de chegadas de veículos à praça e o tempo de atendimento foram estabelecidos na simulação a partir das observações realizadas, já que são aspectos da simulação sobre os quais o usuário tem controle total. Os processos de escolha de cabines e mudanças de faixas são determinados unicamente pelas lógicas internas do simulador, que não podem ser modificadas pelo usuário. Outros aspectos, como o processo de aceleração e desaceleração, foram estabelecidos indiretamente, já que o usuário pode apenas estabelecer características de desempenho dos veículos usados na simulação tais como potência efetiva do motor, peso, etc. Na construção do simulador, procurou-se criar uma rede cuja operação representasse o mais fielmente possível o funcionamento de uma praça real de pedágio, dentro das limitações de recursos e de tempo.

Adicionalmente, considerando-se que o propósito da simulação era apenas ilustrar a aplicação dos parâmetros que caracterizam a operação de praças de pedágio, optou-se por uma validação simplificada do modelo de simulação, baseada na observação do comportamento dos veículos. O simulador foi considerado validado quando o comportamento dos veículos era compatível com o esperado.

\subsection{Experimentos de simulação}

Vários experimentos de simulação foram realizados para verificar o efeito da variação da taxa de fluxo horário e da composição do tráfego sobre o sistema. Foram consideradas duas medidas de desempenho para a análise dos dados gerados pela simulação: o tempo médio gasto no sistema (considerada a medida de desempenho primária) e o comprimento médio de fila por cabine.

\subsection{Cenários simulados}

O objetivo das simulações realizadas foi determinar como as medidas de desempenho adotadas variam com o aumento do fluxo de veículos e com a porcentagem de veículos equipados para a cobrança de pedágio por meio do sistema AVI. Para tanto, foi preciso determinar a capacidade teórica da praça de pedágio.

Para o cálculo da capacidade da praça, considerouse uma composição básica do fluxo de tráfego $(70 \%$ de automóveis e $30 \%$ de caminhões) e um tempo médio de atendimento de $22 \mathrm{~s}$ para os automóveis e $35 \mathrm{~s}$ para os caminhões. A capacidade calculada foi de 556 veíc/h. Dessa forma, foram criados cenários nos quais o fluxo de tráfego variava de 100 a 600 veíc/h (com incrementos de 100 veíc/h) e a porcentagem de veículos usando o sistema AVI variava de $0 \%$ a $20 \%$ (com incrementos de 5\%).

\subsection{Discussão dos resultados obtidos na simulação}

As Figuras 2 e 3 mostram a variação das medidas de desempenho adotadas de acordo com o fluxo e a composição do tráfego. Nelas, os pontos referem-se aos resultados das simulações e as curvas são interpolações arbitrárias entre os valores obtidos. $\mathrm{O}$ termo "Sem pedágio", na Figura 2, refere-se ao tempo de viagem ao longo dos $1.700 \mathrm{~m}$ da rede simulada quando não existem cabines de pedágio.

Através da observação das figuras apresentadas fica evidente que o uso de cobrança eletrônica de pedágio reduz consideravelmente o congestionamento na praça de pedágio. Quando o fluxo de tráfego se aproxima da capacidade, se apenas $10 \%$ dos usuários estiverem equipados com tags AVI, o tempo médio gasto no sistema pode ser reduzido quase à metade, comprovando os benefícios gerados por essa tecnologia de cobrança. Portanto, seria extremamente conveniente que as concessionárias passassem a incentivar o uso das cabines AVI, eliminando ou reduzindo a cobrança da taxa mensal dos usuários e/ou o valor cobrado na aquisição do tag. Outro tipo de incentivo à adoção do sistema AVI de pagamento de tarifa seria a construção de faixas especiais para veículos portadores de tags, que permitiriam que esses usuários evitassem os congestionamentos que se formam na entrada das praças em 


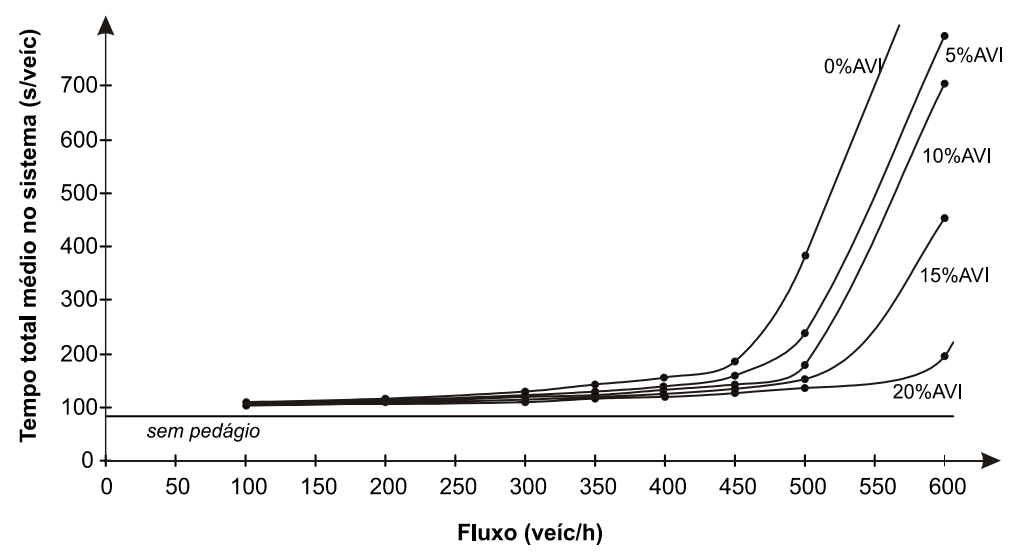

Figura 2: Resultados obtidos na simulação para o tempo médio gasto no sistema

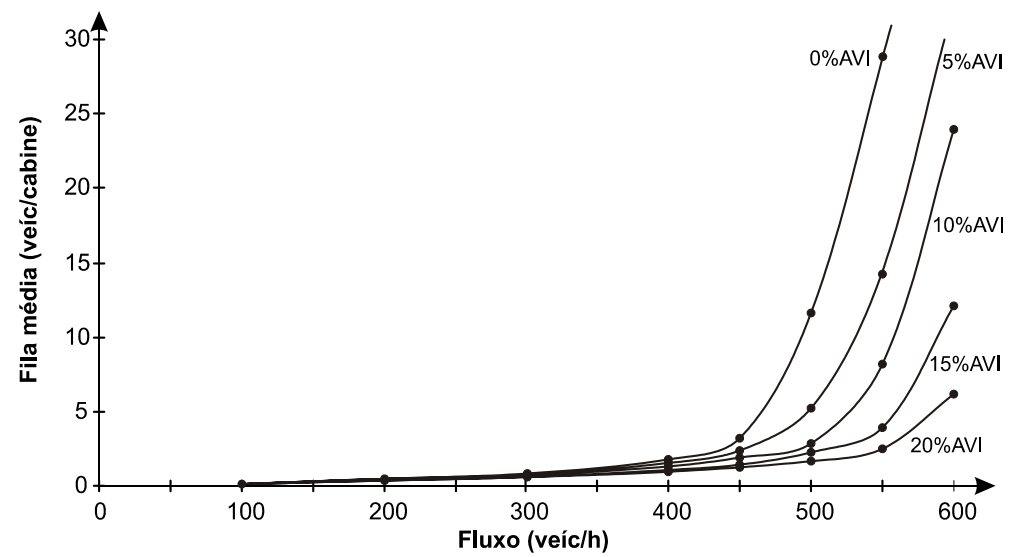

Figura 3: Resultados obtidos na simulação para o comprimento médio de fila por cabine

períodos de movimento intenso, como em feriados prolongados.

\subsection{Método para estabelecimento de critérios para avaliação do nível de serviço}

O método proposto é baseado no uso do modelo de simulação citado anteriormente. $\mathrm{O}$ passo inicial seria estabelecer a capacidade da praça com base, por exemplo, em uma definição tal como o maior fluxo no qual a fila limita-se à praça de pedágio, sem propagarse pela rodovia. A capacidade deve corresponder ao nível de serviço E. Os limites dos demais níveis de serviço seriam estabelecidos em função do tempo médio no sistema. Por exemplo, o limite do nível de serviço A poderia ser estabelecido considerando-se que o tempo médio no sistema não deve ultrapassar a soma do tempo de atendimento do veículo com a metade do tempo de atendimento de outro veículo, o que corresponderia a menos de um veículo na fila.

Uma vez estabelecidos os limites dos níveis de serviço, a verificação operacional do nível de serviço na praça seria realizada através do comprimento médio das filas, já que é muito mais simples observar a extensão da fila do que medir o tempo médio no sistema. A correlação entre essas duas medidas de desempenho pode ser feita através de um modelo de simulação.

A Tabela 7 apresenta um conjunto arbitrário de critérios de avaliação do nível de serviço para a praça simulada, baseado na fila média (veíc/cabine), estabelecido puramente para demonstrar como o método proposto funciona. A Figura 4 mostra como a correlação entre o critério de nível de serviço (fila média) e o fluxo médio pode ser feita a partir dos resultados da simulação. O nível de serviço E compreende fila média entre 5 e 30 veíc/cabine, sendo o limite superior a capacidade da praça. A Figura 4 mostra apenas a região das curvas em que a fila média é inferior a 8 veíc/cabine, para facilitar a visualização dos níveis de serviço A a D.

Tabela 7: Critérios para definição do nível de serviço a partir da fila média

\begin{tabular}{cc}
\hline Nível de Serviço & Fila Média (veíc/cabine) \\
\hline A & $\leq 1$ \\
B & $\leq 2$ \\
C & $\leq 3$ \\
D & $\leq 5$ \\
E & $\leq 30$ \\
F & $>30$ \\
\hline
\end{tabular}

Obtidos os fluxos máximos de serviço, podem-se definir as faixas de tempo médio no sistema, correspondentes a cada nível de serviço, usando-se o gráfico da Figura 2. A Tabela 8 mostra os limites dos níveis de serviço assim obtidos, para a situação em que nenhum carro usa tag para pagamento da tarifa $(0 \%$ AVI, nas Figuras 4 e 2). Deve-se ressaltar que os valo- 


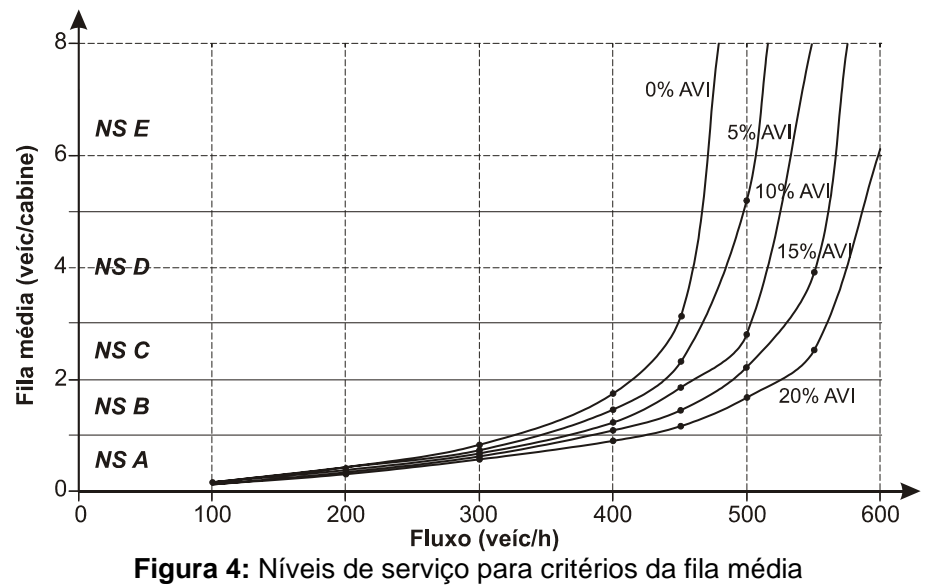

Tabela 8: Fluxos máximos e tempo médio no sistema em função do nível de serviço

\begin{tabular}{cccc}
\hline Nível de Serviço & Fila Média (veíc/cabine) & Fluxo máximo (veíc/h) & Tempo Médio no Sistema (s/veíc) \\
\hline A & $\leq 1$ & 316 & $\leq 123$ \\
B & $\leq 2$ & 407 & $\leq 157$ \\
C & $\leq 3$ & 444 & $\leq 180$ \\
D & $\leq 5$ & 462 & $\leq 209$ \\
E & $\leq 30$ & 555 & $\leq 743$ \\
F & $>30$ & $>555$ & $>743$ \\
\hline
\end{tabular}

res mostrados na Tabela 8 servem unicamente para demonstrar a utilização do método proposto, uma vez que são dependentes da praça de pedágio simulada e dos critérios para determinação do nível de serviço, que foram estipulados arbitrariamente neste estudo.

\section{CONCLUSÕES}

Da análise dos dados coletados neste trabalho, pode-se concluir que:

- o processo de chegadas dos veículos às praças de pedágio pode ser representado por uma distribuição exponencial negativa, se o intervalo de tempo em estudo for relativamente curto (uma hora);

- modelos lineares podem ser usados para a determinação do perfil da velocidade durante a desaceleração e a aceleração dos veículos nas praças;

- a maioria dos motoristas escolhe a cabine no mesmo lado em que chega à praça de pedágio e, uma vez selecionado o lado, se dirigem à cabine com menor fila;

- caminhões e ônibus tendem a usar as cabines do lado direito da praça e alguns motoristas se dirigem a uma cabine com fila mesmo quando há cabines disponíveis para o atendimento naquele lado da praça; e

- o tempo de atendimento dos veículos nas cabines varia em função do tipo de veículo, da forma de pagamento e das características da praça com relação ao valor da tarifa, fluxo de tráfego e tipo de usuário predominante.
Com relação aos tempos de atendimento dos veículos, os dados coletados nas cinco praças indicaram que:

- a tecnologia de cobrança da tarifa de pedágio que produz os menores tempos de atendimento é a eletrônica (AVI), já que os veículos não precisam parar para efetuar o pagamento;

- existem vantagens significativas, do ponto de vista do tempo de atendimento, em se ter tarifas inteiras, já que há uma significativa redução no tempo de pagamento quando se compara os tempos médios de atendimento dessa tarifa com os da tarifa fracionada;

- das tecnologias de cobrança de tarifa analisadas, o uso de cartão inteligente é a segunda melhor alternativa em termos do tempo de atendimento, por dispensar a interação com o arrecadador; e

- o uso de cartão de crédito não traz ganhos do ponto de vista do tempo de processamento. Suas vantagens residem na eliminação do dinheiro na transação e em oferecer mais uma opção de pagamento aos usuários.

A diminuição do tempo de atendimento dos veículos é uma meta que deve ser perseguida por todas as concessionárias de rodovias. Tentativas feitas nesse sentido, como a implantação de um sistema próprio de coleta de pedágio e o incentivo à adesão da coleta eletrônica, são sempre válidas quando se pensa em melhorar a operação das praças e aumentar o conforto oferecido aos usuários.

Por fim, com base na análise dos resultados obtidos através do modelo de simulação desenvolvido, pode- 
se concluir que o uso da cobrança eletrônica de pedágio reduz consideravelmente o congestionamento nas praças de pedágio, especialmente quando o fluxo de tráfego se aproxima da capacidade; se $10 \%$ dos usuários optarem pelo pagamento eletrônico da tarifa, o tempo médio gasto na praça reduz-se quase à metade.

\section{AGRADECIMENTOS}

Os autores agradecem o apoio financeiro para o desenvolvimento desta pesquisa fornecido pela FAPESP, sob a forma de uma bolsa de mestrado (proc. 99/04813-7), e pelo CNPq, sob a forma de uma bolsa de produtividade em pesquisa (proc. 301218/92-7). Os dados usados nesta pesquisa foram fornecidos e coletados com o apoio de funcionários das concessionárias AutoBAn, Triângulo do Sol e Vianorte, cujo apoio os autores agradecem.

\section{REFERÊNCIAS BIBLIOGRÁFICAS}

Al-Deek, H. M.; Mohammed, A. A.; Radwan, E. A. (2000). A new model for the evaluation of traffic operations at electronic toll collection plazas. Transportation Research Record: Journal of the Transportation Research Board, n. 1710, p. 1-10.

Araújo, J. J; Setti, J. R. A. (2002). Praças de pedágio do estado de São Paulo: análise de características operacionais. In: Transporte em Transformação VI, Editora Universidade de Brasília, Brasília, p. 145-161.

Bennett, C. R.; Dunn, R. C. M. (1995). Driver deceleration behaviour on a freeway in New Zealand. Transportation Research Record: Journal of the Transportation Research Board, n. 1510, p. 70-75.

Burris, M. W.; Hildebrand, E. D. (1996). Using microsimulation to quantify the impact of electronic toll collection. ITE Journal, v. 66, n. 7, p. 21-24.

Gulewicz, V.; Danko, J. (1995). Simulation-based approach to evaluating optimal lane staffing requirements for toll plazas. Transportation Research Record: Journal of the Transportation Research Board, n. 1484, p. 33-39.

Lin, F. B.; Su, C. W. (1994). Level of service analysis of toll plazas on freeway main lines. Journal of Transportation Engineering, v. 120 , n. 2 , p. $246-263$.

Oliveira, M. L.; Neto, J. M. R.; Cybis, H. B. B. (2003). A influência do tamanho das filas na capacidade de atendimento das praças de pedágio. In: XVII Congresso de Pesquisa e Ensino em Transportes. Anais. Rio de Janeiro, v. 2, p. 1264-1275.

Oliveira, M. L.; Bocanegra, C. W. R.; Cybis, H. B. B. (2004). Avaliação do desempenho de arrecadadores de praças de pedágio com auxílio de um modelo de redes neurais artificiais. XIII PANAM Congresso Panamericano de Engenharia de Trânsito e Transportes, Albany, NY, EUA. CD-ROM.

Oliveira, M. L.; Cybis, H. B. B. (2005). Fatores intervenientes na capacidade de atendimento de praças de pedágio. In: XIX Congresso de Pesquisa e Ensino em Transportes. Anais. Recife, v. 1, p. 891903.

Van Aerde, M. (2000). Integration release 2.3 for Windows: user's guide. V. I e II. Queen's University. Kingston, Ontario, Canadá.

Widmer, J. A.; Iannoni, A.; Funchal, G. (1999). Sistemática para o dimensionamento do número de canais de atendimento em praças de pedágio. In: XII Congresso de Pesquisa e Ensino em Transportes. Anais. São Carlos, v. 1, p. 585-596.

Zarrillo, M. L.; Radwan, A. E.; Al-Deek, H. M. (1997). Modeling traffic operations at electronic toll collection and traffic management systems. Computers \& Industrial Engineering, v. 33, n. 3-4, p. $857-860$ 